\title{
Study on the Innovation Incubation Ability Evaluation of High Technology Industry in China from the Perspective of Value-Chain
}

\section{-An Empirical Analysis Based on 31 Provinces}

\author{
Li Zuo ${ }^{1}$, Jianlin Zhou' ${ }^{2}$, Fengmei Wei ${ }^{3}$ \\ ${ }^{1}$ College of Economics \& Management, Dalian Nationalities University, Dalian, China \\ ${ }^{2}$ Institute of Finance and Accounting, China Petroleum Finance Company, Beijing, China \\ ${ }^{3}$ Finance Department, China National Petroleum Corporation, Beijing, China \\ Email: 1157396703@qq.com, jlzhou@cnpc.com.cn, h2280wfm@cnpc.com.cn
}

How to cite this paper: Zuo, L., Zhou, J.L. and Wei, F.M. (2018) Study on the Innovation Incubation Ability Evaluation of High Technology Industry in China from the Perspective of Value-Chain. Open Journal of Social Sciences, 6, 247-262.

https://doi.org/10.4236/jss.2018.69017

Received: June 8, 2018

Accepted: September 18, 2018

Published: September 21, 2018

Copyright $\odot 2018$ by authors and Scientific Research Publishing Inc. This work is licensed under the Creative Commons Attribution International License (CC BY 4.0).

http://creativecommons.org/licenses/by/4.0/

\section{(c) (i) Open Access}

\begin{abstract}
This paper establishes the evaluation model of innovation incubation ability by using optimal combination weight and analyzes the innovation incubation ability of high technology industry based on data from 31 provinces during the period of 2008-2012. The results show that from general prospective, the innovation incubation ability of high technology industry enters into the slow development phase in accord with "W" shape in China; from the regional prospective, Guangdong, Jiangsu and Beijing are in the lead; Tibet, Ningxia lag behind other regions; the rank of some regions is changeful; from sub-ability prospective, while resource investment ability and research and development ability overall show a downward trend, economic transformation ability shows a upward trend; besides, research and development ability makes more important contribution to the innovation incubation ability of high technology industry.
\end{abstract}

\section{Keywords}

Innovation Incubation Ability, Resource Investment Ability, Research and Development Ability, Economic Transformation Ability

\section{Introduction}

The total production value of high-tech industry is leapfrogging with an average annual growth rate of over 20\% [1]. Meanwhile, some severe challenges such as the lack of industry chain, low-level product technology and added value and gradient patterns in regional development cannot be ignored [2]. To avoid re- 
gional shelling and rural hollowing, we should foster high-tech industries with core competence and long-term potentials. The concept of incubation innovation ability emerged as the goal of industrial incubation was put forward [3], and its social and economic returns spawned extensive attention.

Innovation incubation ability relies on innovation incubation network [4] which mainly regards parent organizations as core carriers, serves high-growth entrepreneurs and aims to incubate high-tech industries. During the transition from corporate incubation into industrial incubation, the mother body, along with other organizations, provides new ventures with initial service support, shared resource and some operating funds [5] [6] in accordance with its expertise and resource network to improve new venture's innovation ability and achievement transformation level, as well as synthetic ability of high-tech potentials [7]. Innovation incubation ability is regarded as a reflection to rate optimization of regional technological innovation structure and function display to promote the sustainable development of high-tech industry in China. To evaluate this innovation incubation ability objectively and scientifically can foster the scientific positioning of a certain area and its feasible cultivation strategy of innovation incubation ability, and it's important to improve the competitive edge of high-tech industry.

Currently, scholars at home and abroad have carried out a series of related researches. To sum up, the existing researches mainly exhibit the following problems: firstly, scholars currently pay more attention to concept connotation and functional objective concerning the research on innovation incubation ability, but they seldom make quantitative assessment. Secondly, researches are now mostly based on microscopic levels, only in the scope of incubators to analyze how to improve the management level and operational mode of incubators or improve the innovation incubation ability [7], which ignore the influences that other carriers in the incubation network have on innovation incubation ability. Thirdly, when the majority of scholars evaluate the ability of innovation incubation, they rarely touch the industrial level, thus resulting in the lack of concerning industry incubator.

In light of the concerns above, on the basis of exploring the conjunction point of value chain and innovation incubation activities, this paper divides the process of high-tech industrial innovation incubation into three sub-phases based on the value-chain framework, which are upstream resource investment, research and development midstream and economic transformation downstream. This method will help separate three main factors, resource, technology and market, from the problem of influencing high-tech industrial system of innovation incubation ability to create a set of sound evaluation index system of innovation incubation ability among regional high-tech industries. Following process and the direction of value chain upgrading of the evaluation index system, innovation incubation ability and its sub-ability can be assessed macroscopically, which can reveal inefficient sections of innovation incubation ability and specifically upgrade the value-chain framework. Thus, high-tech industrial inno- 
vation incubation ability can be improved according to the whole value-chain framework.

This study is to analyze the development status of innovation incubation capability of provinces and cities in China on a basis of 31 provinces during the period of 2008-2012, this paper uses optimal combination weighting method and analyzes China's high-tech industrial innovation incubation ability. The optimal combination weighting method includes G1 method [8], G2 method [9], entropy method [10] and maximize deviation method [11], which can avoid shortages of subjective assessment and objective assessment. The G1 and G2 methods are subjective evaluation methods. Their data are derived from expert experience and subjective judgment. The entropy method and the maximization of variance are objective evaluation methods. Their data are derived from the objective data in China Statistical Yearbook. By combining the weighting method, it can also allocate the contribution that every index makes to innovation incubation ability appropriately, which is conducive to a more rational evaluation result.

\section{Build an Innovation Incubation Ability Index System for High-Tech Industry}

\subsection{Principles}

To build an innovation incubation ability index system for high-tech industry, it is important to select indexes scientifically and rationally. The indexes should follow these principles:

1) Scientific principle. The settings of index system should be in accord with innovation incubation ability's connotation.

2) Operative principle. The settings of indexes and index system should have definitions and limits and indexes should be available.

3) Advanced principle. Indexes selected must be able to reflect the condition of innovation incubation ability instantaneously.

4) Systematic principle. Indexes selected must reflect not only resource investment and efficiency condition of innovation incubation ability but also its sustainability and potentials. Stock, relative level and growth level should all be considered. To make an objective and rational evaluation, absolute index, relative index and potential index (growth rate), can be adopted to evaluate rational innovation incubation ability.

\subsection{Evaluation Index System}

Scholars believe that innovation value chain focuses on enterprises, scientific research institutions, colleges and universities, government agencies, investment and financing institutions etc. The value chain model is a process which is about innovation resource investment, emergence of innovative technology and finally the realization of industrialization and marketization of the innovation. In the process, innovative knowledge and technology flow along the value chain in order to realize the innovation value and promote the upgrade of the value chain. The operational process of high-tech industry innovation incubation is with high 
growth startups as the core subject, taking market demand as the guidance, through the effective connection of related innovation subjects such as technical innovation, organizational innovation and management innovation incubator, to achieve the efficient allocation and integration of incubation resources within the innovation incubation network, so as to realize innovative knowledge supply, technology supply and products supply, finally to promote technology industrialization and marketization. Thus, the operational process of high-tech industry innovation incubation system is consistent with the thoughts of innovation value chain. Optimization of high-tech industry innovation incubation system essentially is the realization of the value chain upgrade. Therefore, classification or evaluation of high-tech industry innovation incubation ability at the angle of value chain is scientific.

Table 1. The evaluation index system of innovation incubation ability of high technology industry.

\begin{tabular}{|c|c|c|}
\hline Criteria layer & Index layer & \\
\hline \multirow{12}{*}{$\begin{array}{l}\text { (T1) } \\
\text { Resource investment ability }\end{array}$} & (T11) Expenditure on R \& D & \multirow{5}{*}{ Reflect Financial Input } \\
\hline & (T12) Expenditure on S \& $\mathrm{T}$ & \\
\hline & (T13) Local Financial Appropriation for S \& $\mathrm{T}$ & \\
\hline & (T14) Amount of Venture Capital & \\
\hline & (T15) Implementation Fund of Industrialization Project & \\
\hline & (T16) Number of R \& D Personnel & \multirow{7}{*}{$\begin{array}{l}\text { Reflect the Input of Innovation } \\
\text { Carrier }\end{array}$} \\
\hline & (T17) Number of S \& T Personnel & \\
\hline & (T18) Number of Entrepreneurial Mentor in Incubator & \\
\hline & $\begin{array}{l}\text { (T19) Number of Management Services and Professional and Technical } \\
\text { Personnel in Incubator }\end{array}$ & \\
\hline & (T110) Number of National Incubators & \\
\hline & (T111) Number of Nationally Recognized Technology Centers & \\
\hline & (T112) Investment in Public Technology Service Platform & \\
\hline \multirow{7}{*}{$\begin{array}{c}\text { (T2) } \\
\text { Research and development } \\
\text { ability }\end{array}$} & (T21) Number of R \& D Institutions & \multirow{3}{*}{$\begin{array}{l}\text { Reflect the Intensity of Innovative } \\
\text { R \& D }\end{array}$} \\
\hline & (T22) Intensity of R \& D Investment & \\
\hline & (T23) Intensity of New Product Development & \\
\hline & (T24) The Number of Projects A Thousand People Own & \multirow{4}{*}{$\begin{array}{l}\text { Reflect the number of innovative } \\
\qquad \text { R \& D }\end{array}$} \\
\hline & (T25) The Number of New Product Development Projects A Thousand People & \\
\hline & Own & \\
\hline & (T26) The Number of Patents A Thousand People Invent & \\
\hline \multirow{6}{*}{$\begin{array}{c}\text { (T3) } \\
\text { Economic transformation } \\
\text { ability }\end{array}$} & (T31) Output of New product & Reflect the Output of New \\
\hline & (T32) Sales Revenue of New product & Product \\
\hline & (T33) Annual growth rate of incubating enterprises & \multirow{2}{*}{$\begin{array}{c}\text { Reflect the Emergence of New } \\
\text { Venture }\end{array}$} \\
\hline & (T34) Annual growth rate of high-tech enterprises & \\
\hline & (T35) Prime Operating Revenue of Hi-tech Industries & \multirow{2}{*}{ Reflect the Output of Industry } \\
\hline & (T36) Profit of High-tech Industries & \\
\hline
\end{tabular}


From the prospective of value chain, this paper divides high-tech industry innovation incubation into three stages, namely resource investment, innovation development and economic transformation. And in light of those stages, it constructs regional innovation incubation ability evaluation index system of 24 sub-indexes (Table 1).

\section{Build an Innovation Incubation Ability Evaluation Model for High-Tech Industries}

An innovation incubation ability evaluation model for high-tech industries is on the basis of optimal weights combination method, the specific steps are as follows:

Firstly, collect the raw data of indexes, during which the standardization is required.

Secondly, determine the index weight by single evaluation weighting method such as G1 method, G2 method, entropy method and maximizing deviation method etc.

Thirdly, calculate the combination weight coefficient of different evaluation methods so as to calculate the combination weight.

Finally, calculate and rank the innovation capacity score of evaluated objects by empirical analysis as Figure 1 shows [12].

\subsection{Standardized Process of Raw Data}

$x_{i j}$ is set to represent the value of the $f^{\text {th }}$ index of the $i^{\text {th }}$ object after the standardized process; $V_{i j}$ is set to represent the $f^{\text {th }}$ index of the $i^{\text {th }}$ object. $n$ represents the number of evaluated objects. Because all the indexes are positive, the standardized processing is based on positive scoring formula [13].

$$
x_{i j}=\frac{v_{i j}-\min _{1 \leq i \leq n}\left(v_{i j}\right)}{\max _{1 \leq i \leq n}\left(v_{i j}\right)-\min _{1 \leq i \leq n}\left(v_{i j}\right)}
$$
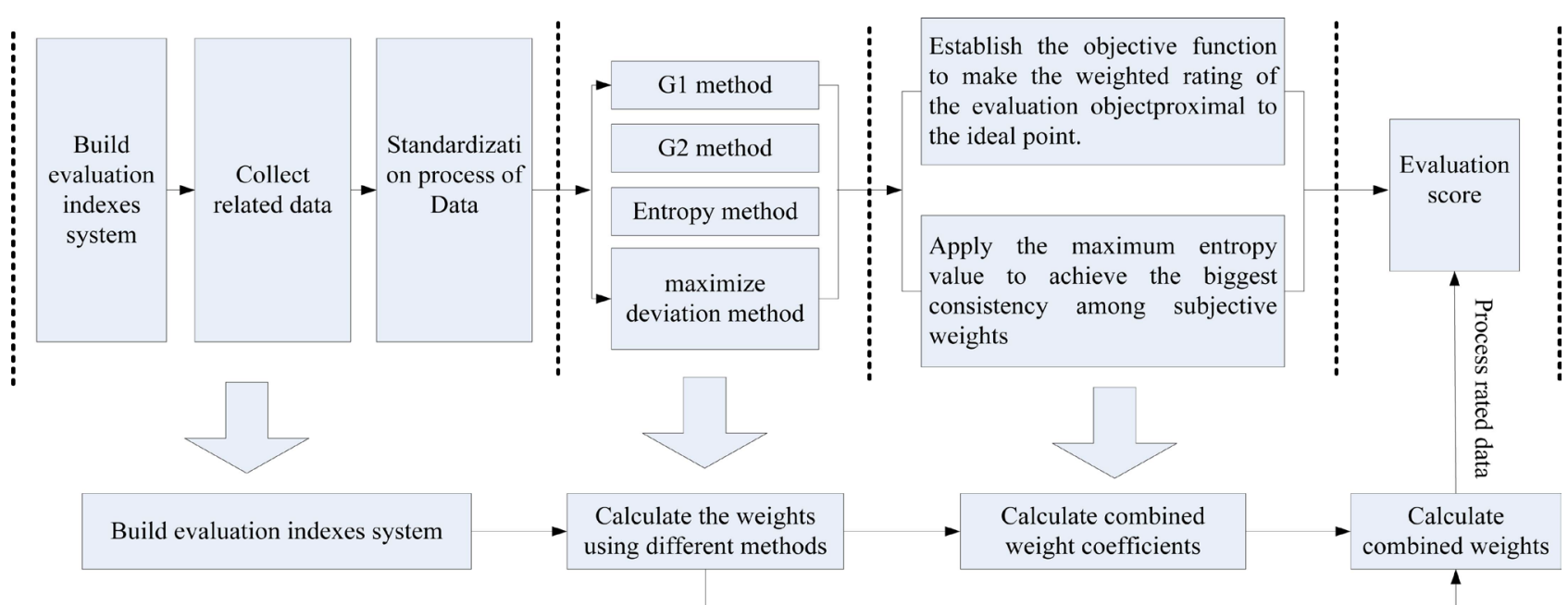

Figure 1. The innovation incubation ability of high technology industry based on optimal combination weight. 


\subsection{Single Evaluation Weighting Method}

1) G1 method

G1 method is a subjective evaluation method which shows the importance of the index by experts' subjective ranking [8].

a) Determine the order relation of indexes, namely subjectively judging the degree of importance between different indexes.

b) Subjectively give weight to the degree of importance $\left(R_{i}\right)$ of adjacent indexes $\left(x_{i}\right.$ and $\left.x_{i-1}\right)$.

c) Calculate the weight of the $k^{\text {th }}$ index by using formula (2)

$$
w_{k}=1 /\left(1+\sum_{i=2}^{k} \Pi R_{i}\right)
$$

d) According to the weight $w_{k}$, the weight of the $K-1^{\text {th }} \ldots 3^{\text {rd }}$ and $2^{\text {nd }}$ index can be known, as shown in formula (3).

$$
w_{i-1}=R_{i} * w_{i}
$$

2) G2 method

G2 method is also a subjective evaluation method, but it is different from G1 method, which requires the experts to determine the least important index [9].

a) Determine the order relation of indexes, namely subjectively judging the degree of importance between different indexes.

b) Determine the least important index Xk by experts.

c) Experts determine and give subjective weight to the degree of importance between $\mathrm{Xk}$ and other index Xi.

d) Calculate the weight of the $I^{\text {th }}$ index by using formula (4).

e) Note: $w_{i}$ represents the weight of the $I^{\text {th }}$ index. $D_{i}$ represents the subjective weight given by experts.

$$
w_{i}=D_{i} / \sum_{i=1}^{k} D_{i}
$$

3) Entropy method

Entropy method shows the importance of index by calculating the difference of the same index. The larger the value is, the more important the index is [10].

a) Calculate the proportion $r_{i j}$ of the index by using formula (5).

Note: $x_{i j}$ represents the original value of the $f^{\text {th }}$ index of the $i^{\text {th }}$ object, $i=1,2, \cdots, n ; j=1,2, \cdots, m$;

$$
r_{i j}=x_{i j} / \sum_{i=1}^{n} x_{i j}
$$

b) Calculate the entropy $e_{j}$ of the $f^{\text {th }}$ index by using formula (6).

Note: $k=1 / \ln n, n$ is index number

$$
e_{j}=-k \sum_{i=1}^{n} r_{i j} \ln \left(r_{i j}\right)
$$

c) Calculate the degree of redundancy of the entropy.

$$
d_{j}=1-e_{j}
$$


d) $w_{j}$ is set to represent the weight of the $f^{\text {th }}$ index, the calculation formula is as follows:

$$
w_{j}=d_{j} / \sum_{j=1}^{m} d_{j}
$$

4) Maximize deviation method

Maximizing deviation method shows the importance of index by calculating the proportion of the deviation of the $f^{\text {th }}$ index accounting for total index deviation [11]. The larger the deviation is, the more important the index is.

a) $s_{i j}$ is set to represent the value of the $f^{\text {th }}$ index of the $i^{\text {th }}$ object after the standardized treatment. $w_{j}$ is set to represent the weight of the $f^{\text {th }}$ index. For the index $j, H_{i j}(w)$ represents the deviation of the index value of the object $i$ and other objects $(k=1,2, \cdots, n)$, thus:

$$
H_{i j}(w)=\sum_{j=1}^{m}\left|s_{i j} w_{j}-s_{i k} w_{j}\right|
$$

b) Calculate the index $j$, the total deviation of all objects and other objects

$$
H_{j}(w)=\sum_{i=1}^{n} \sum_{k=1}^{n}\left|s_{i j}-s_{i k}\right| w_{j}
$$

c) According to the deviation maximization principle, create optimizing model.

$$
\begin{aligned}
& \max H(w)=\sum_{j=1}^{m} \sum_{i=1}^{n} \sum_{k=1}^{n}\left|s_{i j}-s_{i k}\right| w_{j} \\
& \text { s.t. }\left\{\begin{array}{l}
w_{j} \geq 0 \\
\sum_{j=1}^{m} w_{j}^{2}=1
\end{array}\right.
\end{aligned}
$$

d) Calculate and normalize the above model so as to get the weight of deviation method.

$$
w_{j}=\frac{\sum_{i=1}^{n} \sum_{k=1}^{n}\left|s_{i j}-s_{i k}\right|}{\sum_{j=1}^{m} \sum_{i=1}^{n} \sum_{k=1}^{n}\left|s_{i j}-s_{i k}\right|}
$$

\subsection{Calculate the Combination Weight Coefficient}

Calculating the combination weight coefficient $a_{c}$ is based on the following two factors:

$$
\sum_{c=1}^{s} a_{c}=1(s=1,2,3,4)
$$

1) Ensure the minimization of generalized distance between weightings and ideal point [14]. $l_{i}$ represents the generalized distance between weightings of each objective and ideal point. $w_{j}^{c}$ represents the weighting of the $f^{\text {th }}$ indicator using weighting method $c . x_{i j}$ represents the value of the $f^{\text {th }}$ indicator of the $I^{\text {th }}$ objective after standardization processing. 
2) Use Jaynes maximum entropy principle to reflect the degree of consistency between each weighted result. Based on the Principle of minimum differentiation between each weighted result, the objective function (14) is defined.

$\theta(0 \leq \theta \leq 1)$ is the balance coefficient between two objects. Referring to the literature of [14] $\theta=0.5$

$$
\begin{aligned}
& \min \theta \sum_{i=1}^{n} \sum_{j=1}^{m} \sum_{c=1}^{s} a_{c} w_{j}^{c}\left(1-x_{i j}\right)+(1-\theta) \sum_{c=1}^{s} a_{c} \ln a_{c} \\
& \text { s.t. } \sum_{c=1}^{s} a_{c}=1, x_{c} \geq 0
\end{aligned}
$$

3) Calculate combination coefficient by the Lagrangian function

$$
a_{c}=\frac{\exp \left\{-\left[1+\theta \sum_{i=1}^{n} \sum_{j=1}^{m} w_{j}^{c}\left(1-x_{i j}\right) /(1-\theta)\right]\right\}}{\sum_{c=1}^{s} \exp \left\{-\left[1+\theta \sum_{i=1}^{n} \sum_{j=1}^{m} w_{j}^{c}\left(1-x_{i j}\right) /(1-\theta)\right]\right\}}
$$

\subsection{Calculate the Combination Weight}

Calculate the weight $w_{c}(c=1,2,3,4)$ of each index by using G1 method, G2 method, entropy method and maximizing deviation method respectively to calculate the combination weight using formula (16)

$$
w=\sum_{c=1}^{s} a_{c} w_{c}
$$

Time the transposed $w^{T}$ of the weight calculated by formula (16) and the standardized treatment of each index. The result equals to the innovation capability evaluation score $S$ of high and new technology industries of each province in China (Autonomous regions and municipalities).

$Q_{i}(i=1,2,3, \cdots, n)$ represents the score of each region.

$$
S=w^{\mathrm{T}} \times X=\left(Q_{1}, Q_{2}, Q_{3}, \cdots, Q_{n}\right)
$$

\section{Empirical Analysis}

The raw data of this paper are selected from China Statistical Yearbook on Science \& Technology, China Statistical Yearbook on High-tech Industry, China Torch Statistical Yearbook and Ministry of Science and Technology Website during 2008 and 2012. After getting related raw data, this paper processes the calculates $x_{i j}$ in formula (1) $(i=1,2, \cdots, 31 ; j=1,2, \cdots, 24)$. This paper will only calculate the data in 2012 (See Table 2). The combined weight coefficients about the Evaluation Index from 2008 to 2012 are described in Table 3. The combination weights of each index from 2008 to 2012 are described in Table 4. In addition, according to Table 4 , the combination weights of resources investment ability, innovative research and development ability, economic transformation ability from 2008 to 2012 were $0.0392,0.0484$, and 0.0416 respectively. Calculate the total score of the annual evaluation objects and each score of criteria layer, as can be seen in Table 5 . 
Table 2. The evaluation index weight of the innovation incubation ability of high technology industry (2012).

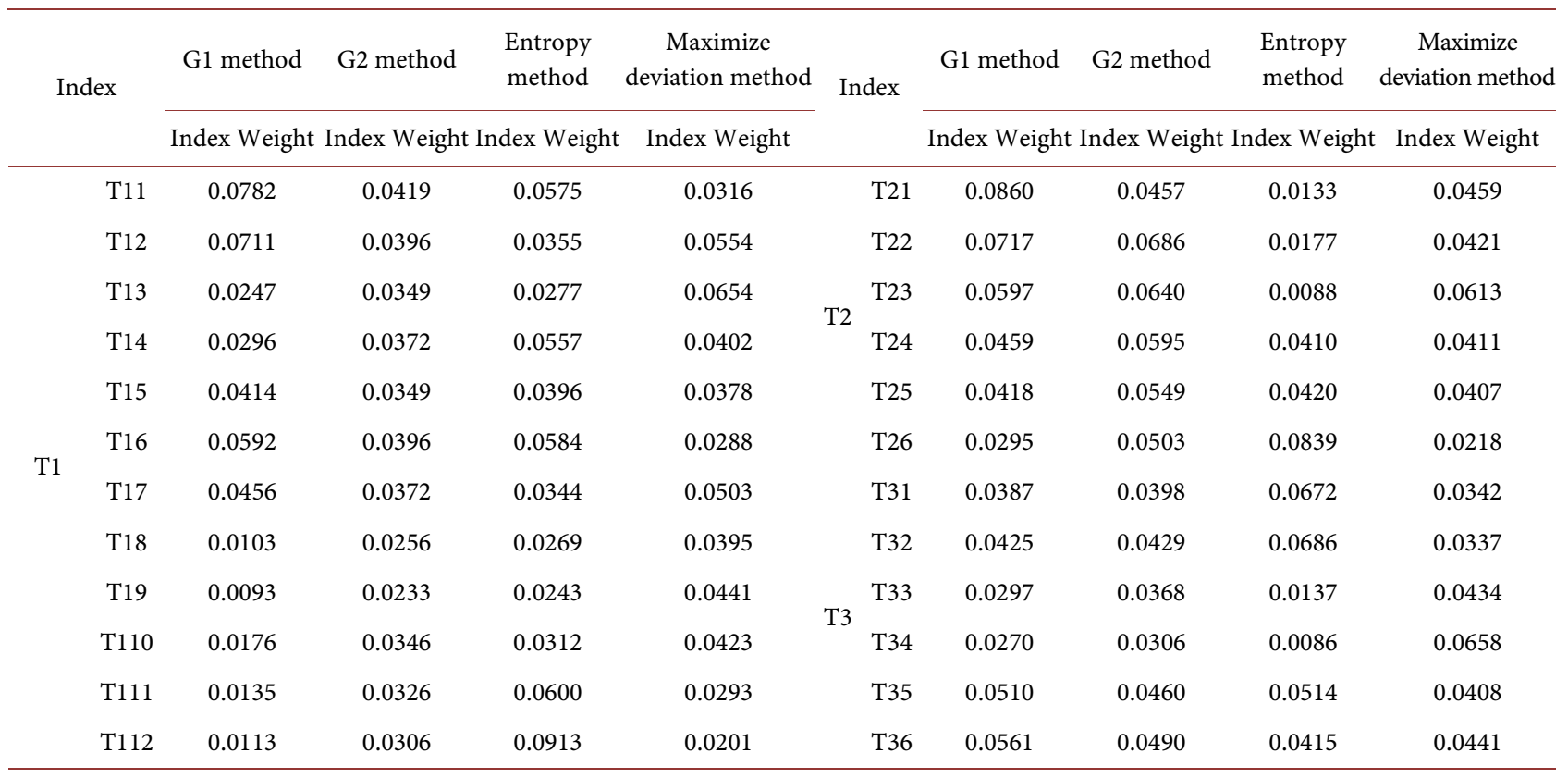

Table 3. The combined weight coefficients about the evaluation index of innovation incubation ability of high technology industry (2008-2012).

\begin{tabular}{ccccccc}
\hline & 2008 & 2009 & 2010 & 2011 & 2012 \\
\hline G1 method & 0.2253 & 0.2445 & 0.2639 & 0.2985 & 0.3062 \\
G2 method & 0.2223 & 0.2280 & 0.2400 & 0.2600 & 0.2147 \\
Entropy method & 0.0374 & 0.1198 & 0.0756 & 0.0743 & 0.0459 \\
Maximize deviation method & 0.5150 & 0.4077 & 0.4205 & 0.3671 & 0.4333 \\
\hline
\end{tabular}

Table 4. The combined weight about the evaluation index of innovation incubation ability of high technology industry (2008-2012).

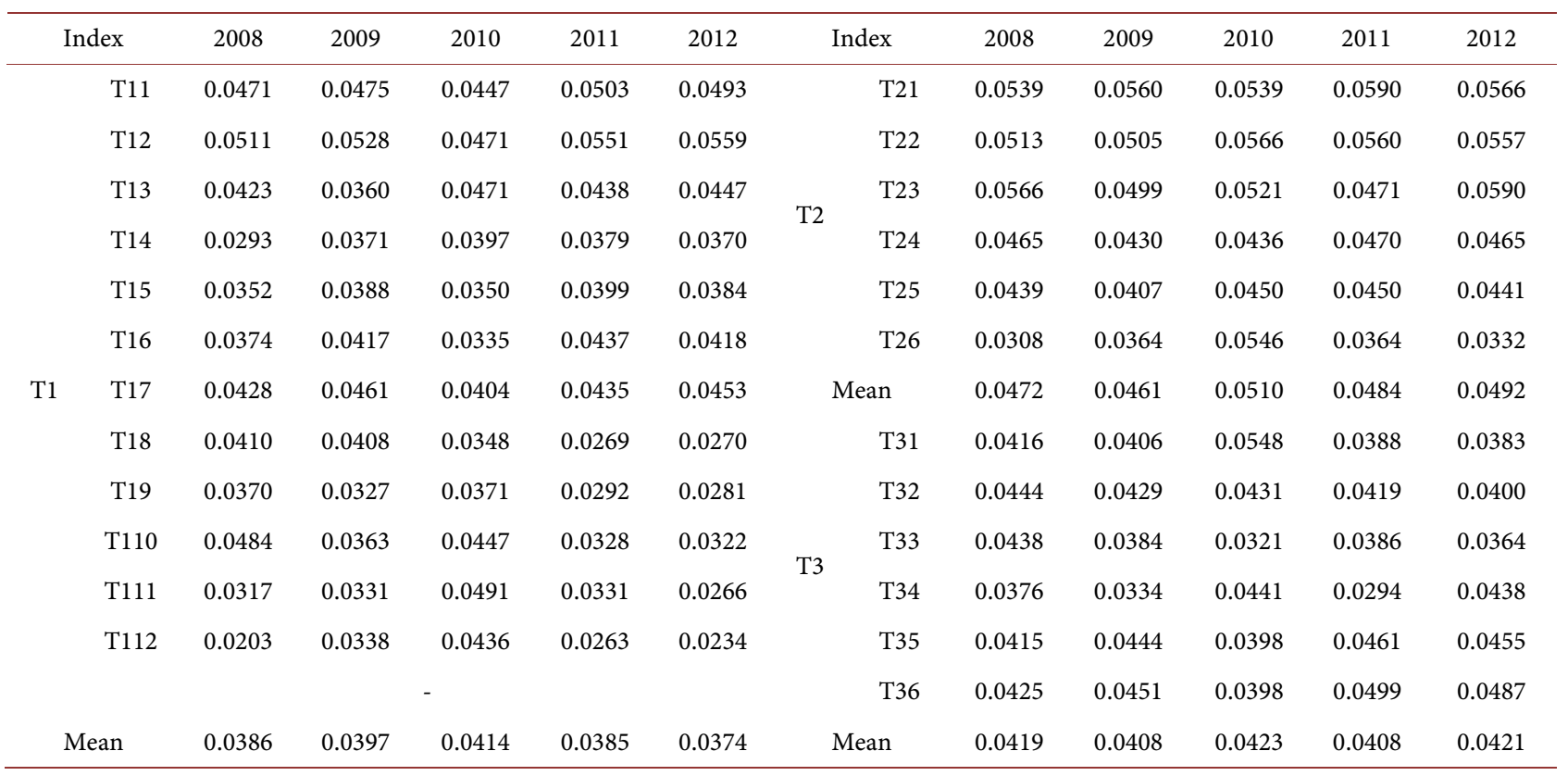


Table 5. The combined evaluation scoring \& ranking about innovation incubation ability of high technology industry in provinces between 2008 and 2012.

\begin{tabular}{|c|c|c|c|c|c|c|c|c|c|c|c|c|}
\hline \multirow{2}{*}{ Region } & \multicolumn{2}{|c|}{2008} & \multicolumn{2}{|c|}{2009} & \multicolumn{2}{|c|}{2010} & \multicolumn{2}{|c|}{2011} & \multicolumn{2}{|c|}{2012} & \multicolumn{2}{|c|}{ Mean } \\
\hline & Score & Rank & Score & Rank & Score & Rank & Score & Rank & Score & Rank & Score & Rank \\
\hline Beijing & 0.5229 & 3 & 0.3882 & 3 & 0.3445 & 3 & 0.3575 & 4 & 0.4042 & 3 & 0.4035 & 3 \\
\hline Tianjin & 0.2561 & 7 & 0.1937 & 8 & 0.1540 & 13 & 0.1578 & 8 & 0.1855 & 10 & 0.1894 & 8 \\
\hline Hebei & 0.1373 & 18 & 0.1021 & 16 & 0.1205 & 17 & 0.1128 & 16 & 0.1069 & 22 & 0.1159 & 16 \\
\hline Shanxi & 0.1226 & 19 & 0.0659 & 26 & 0.0997 & 20 & 0.0767 & 25 & 0.1484 & 13 & 0.1027 & 20 \\
\hline Inner Mongolia & 0.0596 & 28 & 0.0641 & 27 & 0.0835 & 27 & 0.0694 & 26 & 0.0743 & 28 & 0.0702 & 28 \\
\hline Liaoning & 0.1888 & 12 & 0.1898 & 9 & 0.1954 & 8 & 0.1525 & 10 & 0.1759 & 11 & 0.1805 & 10 \\
\hline Jilin & 0.1005 & 23 & 0.0950 & 18 & 0.0875 & 24 & 0.0862 & 21 & 0.0997 & 23 & 0.0938 & 24 \\
\hline Heilongjiang & 0.1626 & 14 & 0.0799 & 22 & 0.0996 & 21 & 0.1060 & 17 & 0.1108 & 21 & 0.1118 & 25 \\
\hline Shanghai & 0.3986 & 5 & 0.3635 & 5 & 0.3165 & 6 & 0.2948 & 6 & 0.3337 & 5 & 0.3414 & 5 \\
\hline Jiangsu & 0.5960 & 2 & 0.6559 & 2 & 0.6316 & 2 & 0.6347 & 2 & 0.6825 & 1 & 0.6401 & 2 \\
\hline Zhejiang & 0.4486 & 4 & 0.3780 & 4 & 0.3380 & 4 & 0.4003 & 3 & 0.3214 & 6 & 0.3773 & 4 \\
\hline Anhui & 0.1618 & 15 & 0.1470 & 13 & 0.1563 & 12 & 0.1555 & 9 & 0.2042 & 9 & 0.1650 & 13 \\
\hline Fujian & 0.2073 & 10 & 0.1820 & 11 & 0.1505 & 14 & 0.1476 & 11 & 0.1465 & 14 & 0.1668 & 12 \\
\hline Jiangxi & 0.1347 & 19 & 0.0805 & 21 & 0.1161 & 18 & 0.0910 & 19 & 0.1400 & 15 & 0.1125 & 18 \\
\hline Shandong & 0.3793 & 6 & 0.3266 & 6 & 0.3272 & 5 & 0.3218 & 5 & 0.3427 & 4 & 0.3395 & 6 \\
\hline Henan & 0.1885 & 13 & 0.1092 & 15 & 0.1610 & 11 & 0.1432 & 13 & 0.1562 & 12 & 0.1516 & 14 \\
\hline Hubei & 0.1941 & 11 & 0.1855 & 10 & 0.1987 & 7 & 0.1592 & 7 & 0.2077 & 8 & 0.1890 & 9 \\
\hline Hunan & 0.1283 & 20 & 0.1464 & 14 & 0.1451 & 15 & 0.1241 & 15 & 0.1349 & 16 & 0.1358 & 15 \\
\hline Guangdong & 0.7722 & 1 & 0.7371 & 1 & 0.7554 & 1 & 0.7179 & 1 & 0.6745 & 2 & 0.7314 & 1 \\
\hline Guangxi & 0.1003 & 24 & 0.0971 & 17 & 0.1042 & 19 & 0.0904 & 20 & 0.0974 & 25 & 0.0979 & 22 \\
\hline Hainan & 0.0488 & 29 & 0.0357 & 30 & 0.0623 & 28 & 0.0514 & 29 & 0.0901 & 26 & 0.0577 & 29 \\
\hline Chognqing & 0.1539 & 16 & 0.0822 & 19 & 0.1256 & 16 & 0.0796 & 24 & 0.1222 & 18 & 0.1127 & 17 \\
\hline Sichuan & 0.2281 & 9 & 0.1965 & 7 & 0.1736 & 9 & 0.1462 & 12 & 0.2125 & 7 & 0.1914 & 7 \\
\hline Guizhou & 0.1114 & 22 & 0.0763 & 23 & 0.0916 & 22 & 0.1003 & 18 & 0.1184 & 19 & 0.0996 & 21 \\
\hline Yunnan & 0.1502 & 17 & 0.0807 & 20 & 0.0911 & 23 & 0.0623 & 28 & 0.0995 & 24 & 0.0968 & 23 \\
\hline Xizang & 0.0246 & 31 & 0.0230 & 31 & 0.0079 & 31 & 0.0185 & 31 & 0.0425 & 31 & 0.0233 & 31 \\
\hline Shaanxi & 0.2316 & 8 & 0.1671 & 12 & 0.1629 & 10 & 0.1409 & 14 & 0.1341 & 17 & 0.1673 & 11 \\
\hline Gansu & 0.0986 & 25 & 0.0739 & 24 & 0.0526 & 29 & 0.0812 & 23 & 0.0782 & 27 & 0.0769 & 25 \\
\hline Qinghai & 0.0971 & 26 & 0.0405 & 29 & 0.0855 & 26 & 0.0847 & 22 & 0.0620 & 29 & 0.0740 & 27 \\
\hline Ningxia & 0.0835 & 27 & 0.0625 & 28 & 0.0337 & 30 & 0.0462 & 30 & 0.0536 & 29 & 0.0559 & 30 \\
\hline Xijiang & 0.0423 & 30 & 0.0661 & 25 & 0.0857 & 25 & 0.0635 & 27 & 0.1125 & 20 & 0.0740 & 26 \\
\hline Mean & & & & & 0.1 & & 0.1 & & & & & \\
\hline
\end{tabular}


From a global perspective, the average value of China's high-tech industry innovation incubation ability from 2008 to 2012 generally appears to be of the "W" shape, which represents W shape volatility (see Figure 2 ). Although the average value $(0.1772,0.1793,0.1701,0.1895)$ of China's high-tech industry innovation incubation ability increased from 2009 to 2012, the average value is still not more than that (0.2107) in 2008. Thus, from 2008 to 2012, the development of China's high-tech industry innovation incubation ability is relatively slow.

The possible reason for this volatility may be the financial crisis in 2008, during which the development of Chinese high-tech enterprises suffered a series of frustration, due to the influx of a large amount of capital into the real estate industry, investment in high-tech industry has declined, leading to lack of resource investment for incubation ability of high-tech technology industry, thereby reducing the ability of innovation and incubation. Therefore, between 2008 and 2011, innovation incubation ability showed a decline in volatility. Since then, the Chinese government has realized the importance of the hi-tech industry in alleviating the economic crisis and solving the economic sluggishness. The government has increased its support to the hi-tech industry, especially in the construction of high-tech industry incubation carrier, and fundamentally solved the problem of lacking of stimulus of industrial development. In order to cultivate a large number of high-tech start-ups that "focus on the rise" to lay the foundation for the development of high-tech industry, form 2011 to 2012, China's innovation and incubation ability have shown an upward trend.

By calculating average value of high-tech industry innovation incubation ability from all provinces and cities, it can be seen that Guangdong, Jiangsu, Beijing, Zhejiang, Shanghai, Shandong, Sichuan, Tianjin, Hubei and Liaoning are at the top 10 (see Table 5), and Guangdong, Jiangsu and Beijing are at the top 3. However,

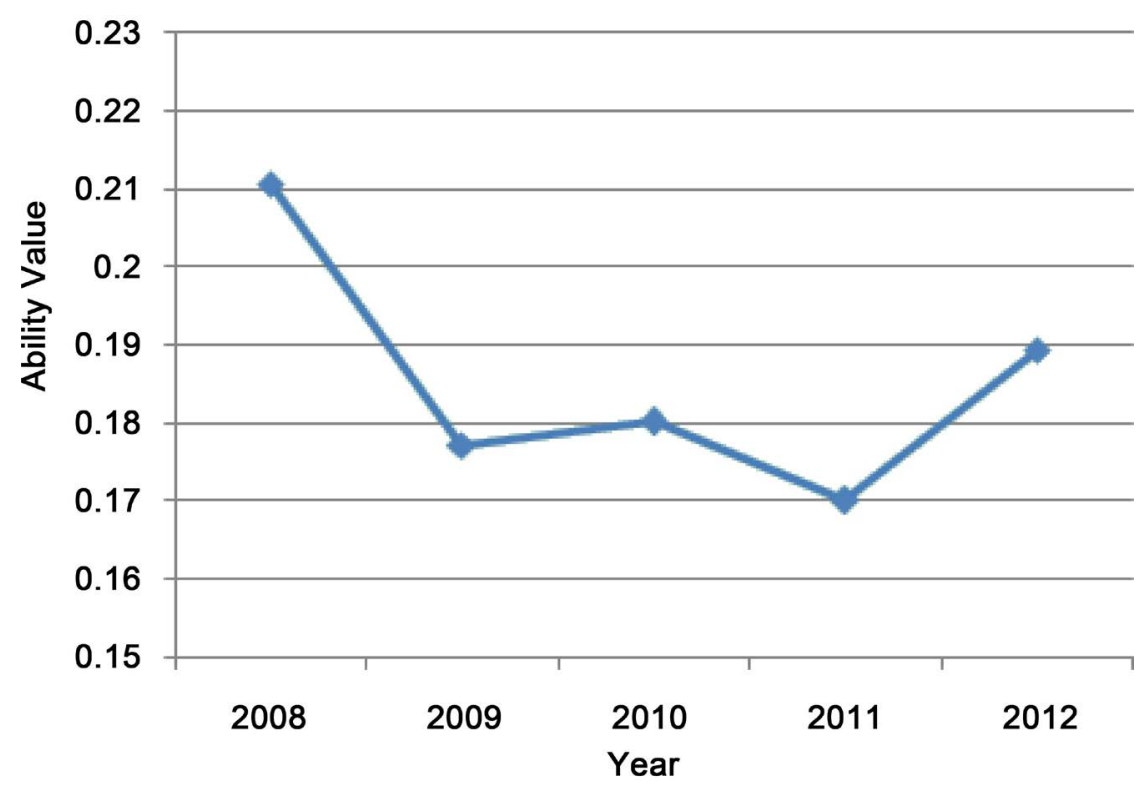

Figure 2. The tendency about innovation incubation ability of high technology industry in China between 2008 and 2012. 
the capacity for Sinkiang, Qinghai, Inner Mongolia, Hainan, Ningxia and Tibet falls behind. The ranking of some provinces and cities vary because of their regional policies. For example, the ranking for Anhui Province rises to $9^{\text {th }}$ place in 2012 from $15^{\text {th }}$ place in 2008 , Heilongjiang falls from $14^{\text {th }}$ place in 2008 to $21^{\text {st }}$ place in 2012. But we can still see synchrony from the tendencies and economic cycles, which to some extent, shows that economic development, marketization degree, government policies and enterprise innovation can influence innovation incubation ability.

Overall, the resource investment capacity and innovation research capacity of China's provinces and cities between 2008 and 2012 declined, whereas the economic transformation capacity grew (see Table 3, Figure 3 ). This may be attributed to the economic instability after the financial crisis in 2008 that made people more prudent and rational on resource investment and innovation development [15]. Since the related data for Tibet and Ningxia are deficient after the year 2008 , it may also influence the average value of resource investment and innovation development capacity. The value of economic transformation capacity grew from the year 2010, which may be attributed to economic recovery and a better market. All provinces and cities regard economic transformation as a vital way to get out of financial crisis, trying to transform from extensive and inefficient featured innovation regions into intensive and efficient ones. This requires a better standard of high-tech industrialization and marketization which can give rise to economic transformation capacity. In addition, from Figure 4, it can be seen that high-tech industrial innovation incubation ability of every province and city accords with its resource investment capacity, innovation research capacity and economic transformation capacity. This shows that high-tech industry innovation incubation ability is reflected by resource investment capacity, innovation research capacity and economic transformation capacity. There are connections

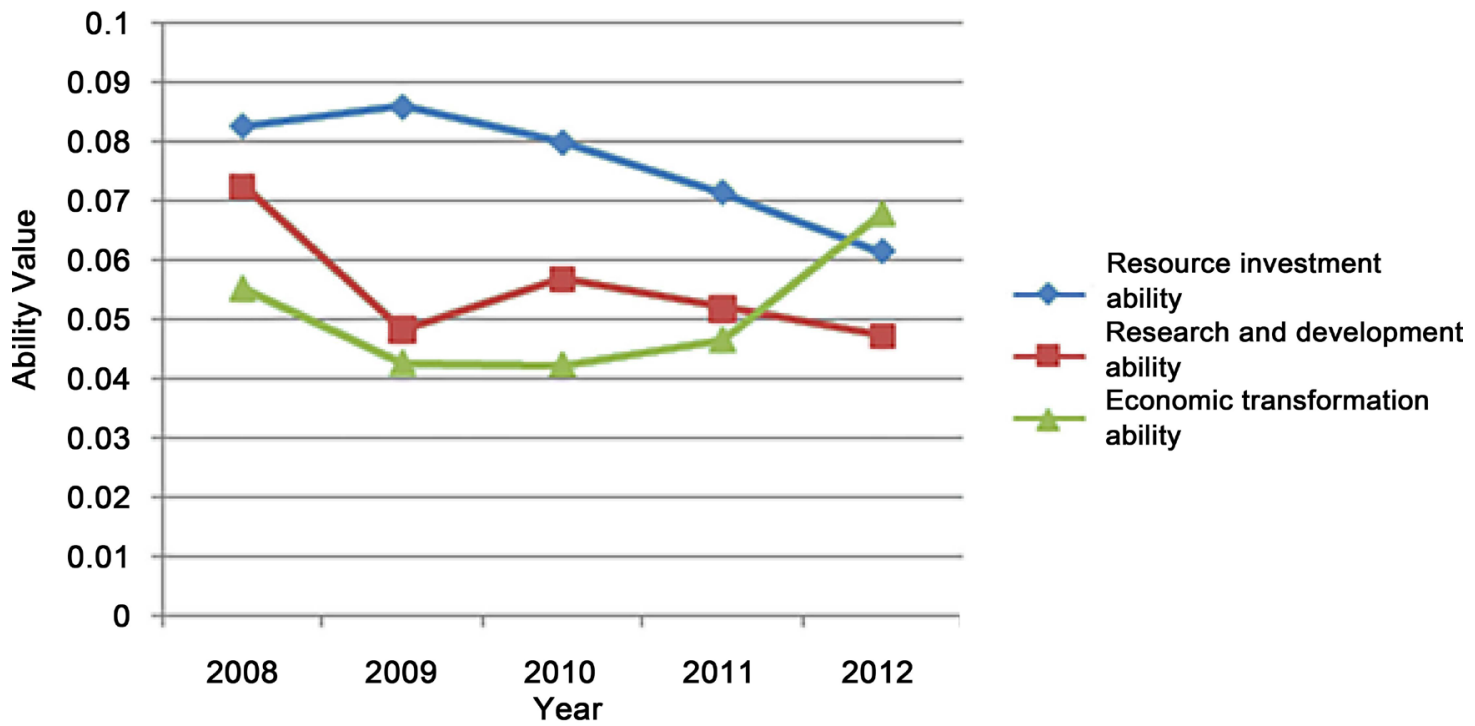

Figure 3. The tendency about innovation incubation sub-ability of high technology industry in China between 2008 and 2012. 


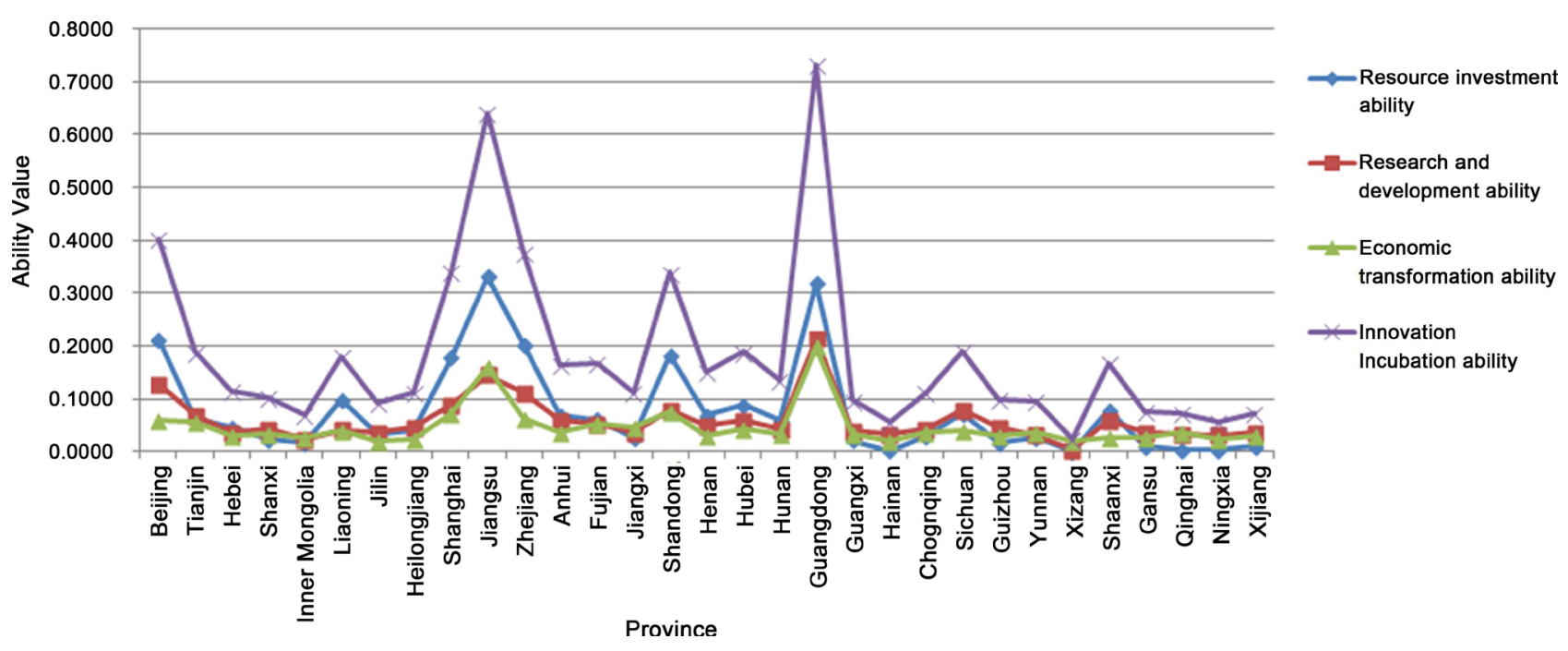

Figure 4. The tendency about innovation incubation ability and sub-ability of high technology industry in provinces between 2008 and 2012 .

among the three capacities and they coordinate with each other in the process of innovation incubation.

\section{Conclusions}

This paper mainly constructs the index system of China's high-tech industrial innovation incubation ability by summarizing relevant literature and combining China's realities and regional development. According to relevant statistical yearbook, it demonstrates high-tech industrial innovation incubation ability from 2008 to 2012. Compared with papers of the same kind, this paper has the following innovations: firstly, based on value-chain framework, this paper aims to achieve innovative resource investment, innovation development and finally the value of innovation. It divides the process of high-tech industrial innovation incubation into upstream resource investment, research and development midstream and economic transformation downstream and it constructs the index system of high-tech industrial innovation incubation ability from aspects of resource investment, innovation research and economic transformation. Secondly, it not only extends the way of evaluating innovation incubation ability, at the scope of incubators but also widens its understanding to regional incubating carriers, which will influence the operation of innovation incubation system but also take multiple innovation carriers into consideration, such as public technological service platform, technical center, etc. It also establishes industrial norm for evaluation index system to embody industrial incubation.

The thesis concludes as follows:

1) Judging from the overall situation of China, the high-tech industrial innovation incubation ability in general is "W" type fluctuation in 2009-2012. The innovation and incubation capabilities in 2009-2012 did not exceed the average score of 2008 which meant in 2009-2012 China's development of high-tech industrial innovation incubation ability was relatively slow. 
2) Judging from various provinces and cities, Jiangsu, Guangdong, Beijing, Zhejiang, Shanghai, Shandong, Sichuan, Tianjin, Hubei, Liaoning and other provinces stood top ten in the innovation and incubation capabilities evaluation, among which Guangdong, Jiangsu, Beijing ranked the top three, whereas Xinjiang, Qinghai, Inner Mongolia, Hainan, Ningxia, Tibet and others were still lagging behind.

3) Judging from sub-competitive abilities, the industrial innovation incubation ability was a combination of resource investment ability, innovative research and development ability and economic transformation ability, among which the innovative research and development ability was the most influential and resource investment ability and economic transformation ability were next in importance. Additionally, through the analysis, in 2008-2012, the overall trend of resource investment ability and industrial innovation incubation ability has been falling, whereas the economic transformation ability has increased.

To realize the reasonable construction and layout of the high-tech industry innovation incubation ability of China, I recommended as follows: a) we need to adjust the investment structure of innovation incubation resource and value the structure and proportion of various investment resources. According to the realities of various provinces and cities, we need to rely on preferential policies or financial input and other means to make up for the lack of resources. b) We need to optimize resource allocation and promote the flowing and combination of advantageous resources among regions. Through matching support, the weak innovation areas need more new resources to boost innovative campaigns and improve the efficiency of output. c) By strengthening the investment in innovation incubation resources to basic research area to promote interaction and connection between basic research and applied research so as to improve the efficiency of innovative research and development, thus fundamentally improve the R \& D capability of high and new technology. d) We need to focus on supporting and cultivating innovative incubator with a greater influence and accelerating the construction of technological achievements transformation platform. Through various forms of innovative cooperation between the main bodies of innovation, we need to actively foster scientific and technological achievements into the market and push forward the high-tech industry development. e) Chinese governments at all levels should accurately hold their own advantages, and constantly improve the infrastructure and financial environment. The government should stop relying on previous rules and enhance its innovation incubation ability by using administrative and marketing means, actively promote the upgrading of regional value chain and industrial chain to achieve a relatively balanced development of regional innovation and incubation capacity.

Although this paper achieves some findings, but there are still some shortages, which requires to be improved in the future. Firstly, this paper does not focus on the mechanism of the impact of various indicators of innovation incubation ability, we can make a deep research and form a new mechanism for future use. Se- 
condly, on further researches, the influence of the external environment factors which can be taken into accounts throughout the whole process of innovation incubation needs, such as financial environment, policy environment, education level, infrastructure construction, etc. Thirdly, the window DEA model can be considered in the future whiling researching, so as to analyze the operational efficiency of the regional innovation incubation system and its subsystem's operating efficiency.

\section{References}

[1] Dan, P. (2016) Dynamics of China's Provincial-Level Specialization in Strategic Emerging Industries. Research Policy, 45, 1586-1603. https://doi.org/10.1016/j.respol.2016.03.022

[2] Jiang, S., Gong, L., Wang, H. and Kimble, C. (2016) Institution, Strategy, and Performance: A Co-Evolution Model in Transitional China. Journal of Business Research, 69, 3352-3360. https://doi.org/10.1016/j.jbusres.2016.02.009

[3] Mian, S.A. (1997) Assessing and Managing the University Technology Business Incubator: An Integrative Framework. Journal of Business Venturing, 12, 251-285. https://doi.org/10.1016/S0883-9026(96)00063-8

[4] Wang, G.H. and Zhou, J.L. (2014) The Model and Simulation for Knowledge Transfer among Innovation Incubation Network Based on Small World Effect. Science of Science and Management of Science \& Technology, 35, 53-63.

[5] Hughes, M., Ireland, R.D. and Morgan, R.E. (2007) Stimulating Dynamic Value: Social Capital and Business Incubation as a Pathway to Competitive Success. Long Range Planning, 40, 154-177. https://doi.org/10.1016/j.lrp.2007.03.008

[6] Tsai, F.S., Hsieh, L.H.Y., Fang, S.C. and Lin, J.L. (2009) The Co-Evolution of Business Incubation and National Innovation Systems in Taiwan. Technological Forecasting \& Social Change, 76, 629-643. https://doi.org/10.1016/j.techfore.2008.08.009

[7] Qiu, G.D. and Ma, H.D. (2010) Research on Regional Innovation System Based on Interaction between Innovation Incubation and Venture Capital. China Soft Science, No. 2, 97-106.

[8] Wang, X.J. and Guo, Y.J. (2006) Analyzing the Consistency of Comparison Matrix Based on G1 Method. Chinese Journal of Management Science, 14, 65-70.

[9] Guo, Y.J. (2002) Comprehensive Evaluation Theory, Method and Application. Science Press, Beijing.

[10] Sakata, M. and Sato, M. (2001) Accurate Structure Analysis by the Maximum-Entropy Method. Acta Crystallographica, 46, 263-270. https://doi.org/10.1107/S0108767389012377

[11] Wei, G.W. (2008) Maximizing Deviation Method for Multiple Attribute Decision Making in Intuitionistic Fuzzy Setting. Knowledge-Based Systems, 21, 833-836. https://doi.org/10.1016/j.knosys.2008.03.038

[12] Chi, G.T., Qi, F. and Zhang, N. (2012) The City's Ecosystem Evaluation Model Based on Optimal Combination Weights and Its Application. Operations Research and Management Science, 2, 183-191.

[13] Li, M.J., Chen, G.H. and Chen, Y.T. (2004) Research on Standardization of Indicators Method of Comprehensive Evaluation. Chinese Journal of Management Science, 12, 45-48.

[14] Li, B.Z., Xu, G.Y. and Su, Y. (2013) Regional Knowledge Acquisition Model Based 
on Optimal Combination Weight: The Empirical Analysis of 31 Provinces. China Soft Science, No. 12, 68-81.

[15] Peng, W., Xu, Z., Zhang, Z., Wu, Y., Deng, H. and Qi, H. (2009) Research on Development Model and Countermeasure of Bamboo Industry in China on International Economic Crisis. International Conference on Electronic Commerce and Business Intelligence, Beijing, 6-7 June 2009, 328-331.

https://doi.org/10.1109/ECBI.2009.77 